\title{
Congenital Malformation Syndrome Related to Known Exogenous Cause
}

National Cancer Institute

\section{Source}

National Cancer Institute. Congenital Malformation Syndrome Related to Known

Exogenous Cause. NCl Thesaurus. Code C101329.

A syndrome characterized by the presence of structural malformations that are present at birth and can be attributed to an exogenous cause. 